\title{
Tecnología, tipología y cronología de las fíbulas de codo antiguas del "tipo Monachil" y sus relaciones mediterráneas
}

\author{
Technology, typology and chronology of Early "Monachil type" elbow fibulae \\ and their Mediterranean relationships
}

\author{
Javier Carrasco Rus (*) \\ Francisco Martínez-Sevilla (*) \\ Juan A. Pachón Romero (*) \\ Ignacio Montero Ruiz (**)
}

\section{RESUMEN}

Se estudia una muestra inédita de fíbulas antiguas de codo lisas, de las consideradas "tipo Monachil", tradicionalmente incluidas en el "grupo sículo" de la Península Ibérica. Se valora su tecnología de elaboración, aleación, tipología y posible cronología. Se comprueba que muestran escasas relaciones con fíbulas de diferentes ámbitos geográficos mediterráneos que, inicialmente, se habían considerado su inspiración.

\begin{abstract}
This paper presents a set of unpublished flat elbow fibulae of the "Monachil" type, which belongs to the wider peninsular Sicilian group. We consider their technological elaboration, smelting alloys, typology, and possible chronology, discovering a certain peninsular autonomy and very little relationship with other Mediterranean areas, which were initially considered their place of origin.
\end{abstract}

Palabras clave: Aleaciones binarias; Bronce Final; Edad del Hierro; Israel; Italia; Península Ibérica; Próximo Oriente; Taller metalúrgico; Sicilia.

Key words: Binary Alloys; Iberian Peninsula; Iron Age; Israel; Italy; Late Bronze Age; Metallurgical Workshop; Near East; Sicily.

(*) Dpto. de Prehistoria y Arqueología. Facultad de Filosofía y Letras. Universidad de Granada. Campus de Cartuja. 18071 Granada. Correos e.:jcrus@ugr.es; martinezsevilla@ugr.es; japr1953@gmail.com

(**) Instituto de Historia. Centro de Ciencias Humanas y Sociales (CSIC). C/ Albasanz 26-28. 28037 Madrid.

Correo e.: ignacio.montero@cchs.csic.es

Recibido: 18-I-2013; aceptado: 9-IV-2013.

\section{INTRODUCCIÓN}

En una reciente investigación (Carrasco et al. 2013) hemos delimitado la fíbula de "tipo Monachil" en el tradicionalmente considerado "grupo sículo" de codo antiguas de la Península Ibérica. Actualmente estaría constituido por unos treinta ejemplares que comparten un codo centrado. Los brazos del puente suelen ser lisos, aunque algunos presentan decoraciones incisas y buriladas con motivos geométricos.

En este extenso y relativamente homogéneo grupo fibular, hemos distinguido subtipos que parecen responder a variaciones tipológicas, cronológicas y conectadas con las aleaciones empleadas para su fundición (Fig. 1). En la fase arcaica (A) tienen cabida las fíbulas que, según criterios tecnológicos y tipológicos, consideramos más antiguas. Responden a un tipo único en todo el arco mediterráneo, cuya ausencia de débitos foráneos, sin embargo, ha sido ignorada en todas las investigaciones sobre el tema, al menos desde las pioneras de Almagro Basch (1940a, 1940b, 1952, $1957,1957-58,1958,1966,1975)$ sobre el conjunto broncíneo de la Ría de Huelva.

El registro arqueológico ofrece escasas asociaciones contextuales para estas fíbulas, como sucede también con los casos considerados antiguos fuera de la Península Ibérica. Pero otros elementos pueden ayudarnos con ciertas garantías a situar, de forma más precisa, este tipo de imperdible en horizontes culturales de la Edad del Bronce, tanto peninsulares como externos. En 


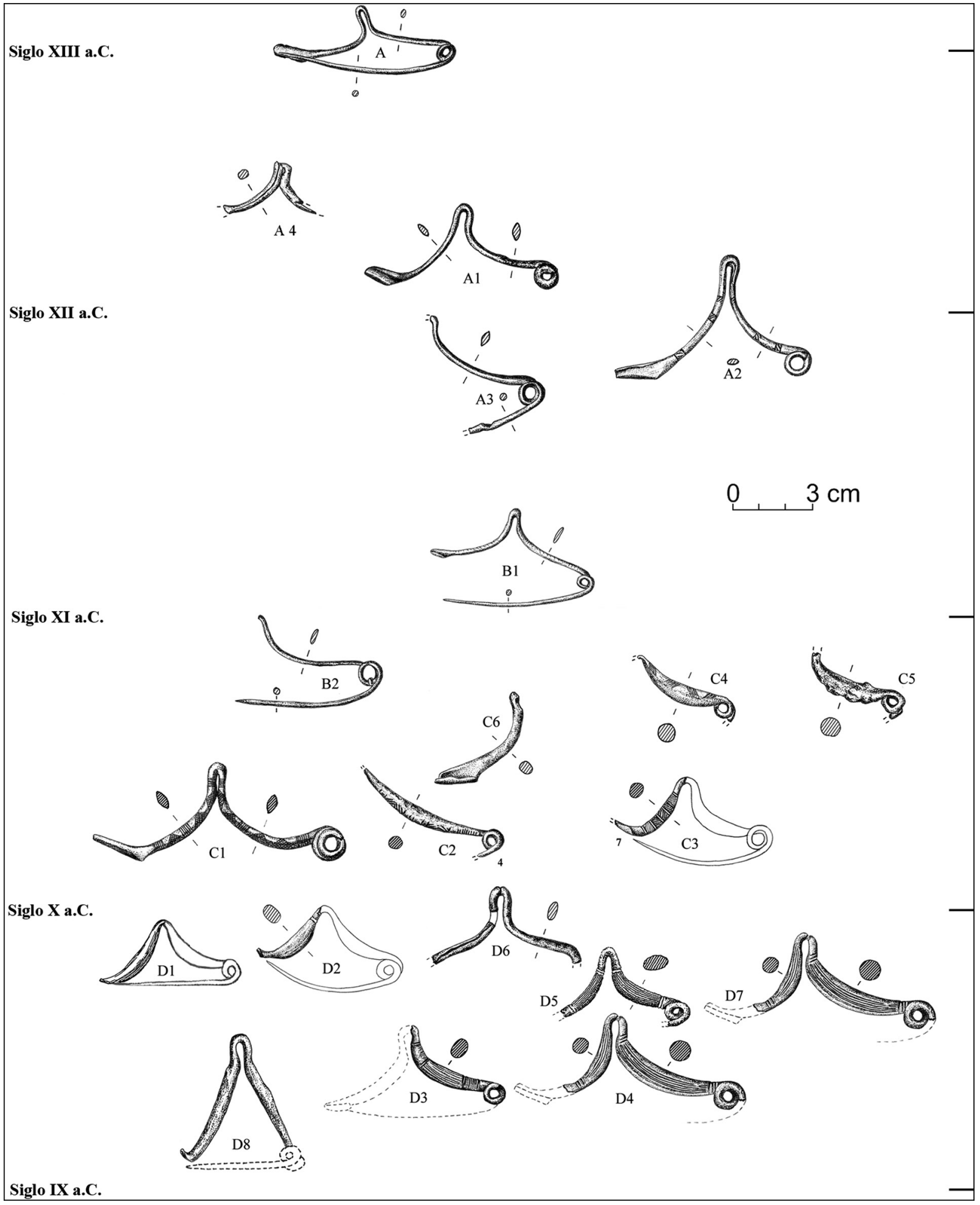

Fig. 1. Tabla crono-tipológica de las fíbulas "tipo Monachil” de la Península Ibérica. 
este artículo proponemos el estudio pormenorizado de la tipología original y el análisis de la tecnología utilizada en su elaboración que por primera vez realizamos, junto con la investigación de la procedencia de las materias primas a partir de las cuales se fundieron, además de algunos otros datos novedosos sobre sus cronologías absolutas.

\section{REGISTRO ARQUEOLÓGICO Y TIPOLOGÍA}

Se han caracterizado, al menos, cinco ejemplares de fíbulas de la fase arcaica (A) del "tipo Monachil" (Fig. 2). Se encontraron en cuatro grandes asentamientos prehistóricos granadinos (Fig. 3), no todos excavados y, en ningún caso, se han localizado las necrópolis del Bronce Final, por lo que, en principio, podemos asegurar su procedencia exclusiva de hábitats. En tres de
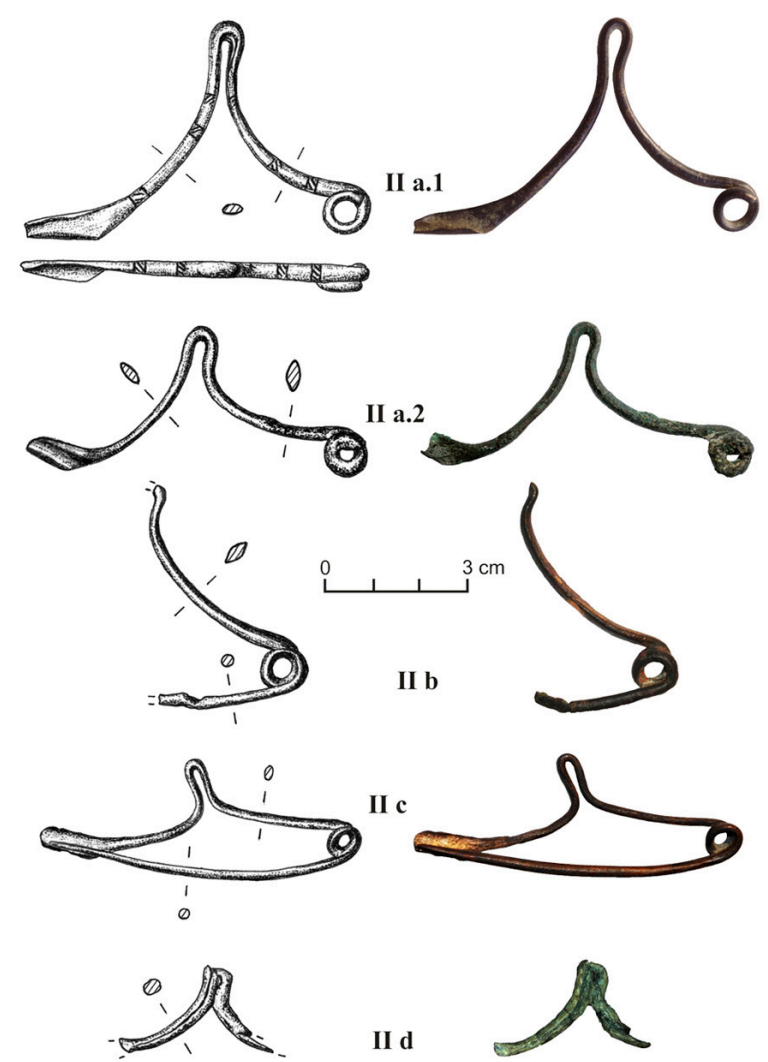

Fig. 2. Fíbulas arcaicas (A) de "tipo Monachil" de la provincia de Granada: IIa1 y IIa.2 Cerro de la Encina, Monachil; IIb Canto Tortoso, Gorafe; IIc Las Muelas, Alamedilla; IId Cerro de la Mora, Moraleda de Zafayona.



Fig. 3. Localización en la Península Ibérica de los hábitats con hallazgos de fíbulas "tipo Monachil": Cerro de la Mora (1); Cerro de la Encina (2); Canto Tortoso (3) y Las Muelas (4).

ellos, hay evidencias directas o indirectas de metalurgia local y tres de las fíbulas son inéditas.

IIa. Cerro de la Encina de Monachil: dos fíbulas (tabla 1) provienen de este importante enclave (Cabré 1922; Arribas et al. 1974; Molina 1977 y 1978), cuya amplia secuencia cultural discurre desde una Edad del Cobre evolucionada con campaniforme hasta época protohistórica. La IIa.1 (Fig. 2), conocida desde antiguo (Schüle 1969), está depositada en el Museo Arqueológico de Granada. La IIa.2 (Fig. 2), inédita, procede de un contexto revuelto (excavaciones 2003/2004). Solo le falta la aguja y media espira del resorte. Los brazos presentan estrechas fajas decorativas paralelas y rellenas de incisiones oblicuas.

IIb. Canto Tortoso de Gorafe: está situado en una amplia meseta en la confluencia de los ríos Fardes y Guadiana Menor, en un área de gran tradición arqueológica, especialmente durante la Prehistoria reciente. Es un asentamiento extenso y sin excavar, conocido por su horizonte protohistórico (González et al. 1995). En superficie se recuperó una fíbula de codo inédita (Fig. 2: IIb), que evidencia una ocupación más antigua. Conserva solo la mitad derecha del puente (tabla 1), con restos del codo, un resorte de espira y media y un fragmento de aguja. Su sección es filiforme.

IIc. Las Muelas de Alamedilla: es un gran yacimiento sin excavar, localizado en la parte nororiental del término municipal de Alamedilla, muy cerca ya de los límites administrativos de la provincia de Jaén. Se sitúa sobre una serie de altozanos calizos (muelas), algunos por encima 


\begin{tabular}{|l|c|c|c|c|c|}
\hline \multicolumn{1}{|c|}{ Fíbula } & Altura & $\begin{array}{c}\text { Anchura } \\
\text { base }\end{array}$ & $\begin{array}{c}\text { Sección } \\
\text { brazos }\end{array}$ & $\begin{array}{c}\text { Longitud } \\
\text { mortaja }\end{array}$ & Bibliografía \\
\hline Cerro de la Encina & 4,7 & 7,4 & $5 \times 2,5$ & 1,6 & $\begin{array}{c}\text { Cabré 1922; Schüle 1969; Arribas } \text { et } \\
\text { al. 1974; Molina 1977, 1978. }\end{array}$ \\
\hline Cerro de la Encina & 3,2 & 7,4 & $6 \times 4$ & 1,1 & Inédita \\
\hline Canto Tortoso & $4,5^{*}$ & $7,7^{*}$ & $6 \times 3,5$ & & $\begin{array}{c}\text { González et al. 1995; Carrasco } \text { et al. } \\
\text { 1999; Carrasco et al. 2012. }\end{array}$ \\
\hline $\begin{array}{l}\text { Las Muelas de } \\
\text { Alamedilla }\end{array}$ & 2,6 & 6,9 & $3,5 \times 2$ & 1,3 & Carrasco et al. 2012. \\
\hline Cerro de la Mora & $2^{* *}$ & $3,2^{* *}$ & 3 & & Inédita \\
\hline
\end{tabular}

Tab. 1. Medidas en mm de las fíbulas "tipo Monachil” (*Aproximado; ** Conservado).

de los 900 m.s.n.m., dominando tierras de secano y regadío, pertenecientes a la cuenca del río Guadahortuna que, junto con la del Guadiana Menor, es la más importante de esta comarca. Desde antiguo se conocen hallazgos superficiales adscribibles a toda la secuencia de la Edad del Bronce y tiempos posteriores. De aquí procede una fíbula inédita completa (Fig. 2: IIc, Tab. 1), con el codo centrado y sección filiforme.

IId. Cerro de la Mora de Moraleda de Zafayona: este extenso conjunto arqueológico dispone de una gran secuencia habitacional, desde época argárica hasta tiempos alto medievales, con énfasis en las ocupaciones del Bronce Final, Fenicia y Protoibérica. Las excavaciones (fines 1970-inicios 1990) proporcionaron una gran variedad de elementos broncíneos, elaborados en talleres metalúrgicos del propio enclave arqueológico. Destacaron, entre otros, los artilugios relacionados con la implementa de vestir, como fíbulas y botones. El yacimiento, dada su extensión, fue dividido, grosso modo, en tres sectores: bajo, alto y aledaños. De estos últimos, en concreto del Cerro de la Miel, dimos a conocer una fíbula de codo de tipo Huelva y una espada de lengua de carpa (Carrasco et al. 1985; Carrasco et al. 1987). De las campañas de excavación en el núcleo principal del sitio, se obtuvieron fíbulas estratificadas: en el sector alto, en contextos del Bronce Tardío y Final, cuatro de "tipo Monachil" y una de pivote; en el sector bajo, con una impresionante secuencia estratigráfica, al menos cinco fragmentos más de fíbulas "tipo Monachil" y, en horizontes posteriores, numerosas de doble resorte. De momento, por su muy mala conservación no han sido analizadas, aunque seguimos valorando hacerlo antes de que su deterioro sea com- pleto. De este importante conjunto antiguo de fíbulas, solo consideramos aquí un ejemplar (Fig. 2: IId) aparecido en un contexto del Bronce Final Antiguo, durante los trabajos de septiembre de 1983. Por morfología, estratigrafía y cronología, quizás pueda iniciar el grupo antiguo (A) de la secuencia fibular (Carrasco et al. 2013) estudiada en el Cerro de la Mora (Fig. 1). Está mineralizada y deformada, su sección es filiforme, faltándole parte de los brazos, resorte, aguja y mortaja salvo su inicio (Tab. 1) y conservando el codo centrado.

La estética de las cinco fíbulas documentadas es similar, con perfiles en forma de triángulo isósceles y bases mayores que las alturas. Los codos están centrados y las secciones son básicamente filiformes. Su elaboración, como posteriormente se comprobará, siguió un mismo patrón por deformación plástica y un acabado con terminación de forja y "limado". Un tipo de manufactura del que no cabe esperar fíbulas con similares dimensiones, terminaciones, complejas decoraciones, etc. La pericia del artesano fue determinante en el resultado final, lo que representa un inconveniente para una posterior y exhaustiva comparativa entre ellas.

El primer subconjunto de la fase arcaica (A) de la serie "Monachil" (Fig. 1) evoluciona hacia formas con secciones más fusiformes, donde poder desarrollar motivos decorativos de mayor complejidad. En otros ejemplares las secciones se hacen más globulosas, empleándose moldes para su fundición, quizás algunos a la cera perdida. El resultado final es heterogéneo, pero se conserva el modelo original de codo centrado y perfil de triángulo isósceles, conformando caracterizaciones y evoluciones estudiadas recientemente de 
modo sucinto (Carrasco et al. 2013). Así, consideramos bastante significativo, dado el origen artesanal de estos imperdibles, que el codo presentase en alguna ocasión su verticalidad, o incluso su perfecta simetría respecto de los brazos constitutivos del puente. Estos rasgos taxonómicos remiten a un modelo común específico, donde se asocian caracteres o atributos repetidos con insistencia en un número consistente de ejemplares (Lo Schiavo 2010: Teil 1:1).

Ese número, cercano a los treinta ejemplares, es en cierta forma ficticio. La mayoría son hallazgos superficiales y aislados, procedentes de hábitats prehistóricos de gran potencial arqueológico sin excavar, pero que a veces y con suerte han podido ser documentados. Su escasa cuantía contrasta con el gran conjunto de otros tipos identificados en ambientes del Mediterráneo Central y Oriental, generalmente procedentes de las extensas y monumentales necrópolis de finales de la Edad del Bronce, ya excavadas de antiguo. En cambio, en la Península Ibérica hasta ahora vienen siendo escasos o inexistentes los conjuntos funerarios excavados de esa época, desconociéndose el potencial que podrían aportar estas fíbulas en un futuro más o menos lejano.

\section{MANUFACTURA: METODOLOGÍA DE ESTUDIO}

La tecnología de manufactura de objetos de base cobre se ha investigado, mayoritariamente, a partir del análisis de la composición elemental. De modo minoritario, aunque creciente en los últimos años, se ha incorporado la metalografía y la identificación de huellas de trabajo o uso en diversos tipos de objetos. Los mecanismos de oxidación y corrosión que afectan al metal de base cobre han sido un factor determinante para el análisis de las huellas de uso en su investigación (Soriano y Gutiérrez 2009; Dolfini 2011; Li et al. 2011), a diferencia de lo que ha sucedido en los metales nobles (Perea y García 2012).

Las investigaciones sobre las fíbulas, centradas en la clasificación tipológica, cronológica y en la composición elemental, apenas cuentan con acercamientos relacionados con sus técnicas de fabricación (Rovira 1987). Dada la excepcionalidad y novedad de las fíbulas que se estudian en este trabajo, consideramos que investigar la manufactura de una de ellas, junto con el resto de datos que aportamos, ayudaría a un conocimiento más exhaustivo de estas piezas. Ello ha sido posible, gracias al excepcional estado de conservación de la fíbula inédita IIc (Fig. 2), cuyo tosco acabado ha permitido reconstruir en primicia el proceso tecnológico de elaboración de estas arcaicas fíbulas de "tipo Monachil".

Las cinco fíbulas seleccionadas se han observado macroscópicamente y con una lupa binocular (0-80x). Además, las imágenes microfotográficas de sus diferentes partes han permitido un cotejo exhaustivo entre ellas. Como algunas técnicas dejan sobre el metal huellas no directamente relacionables con una cierta herramienta o proceso, se han realizado tests experimentales para su contrastación. La praxis comparativa, entre el proceso de trabajo del pasado y del presente, se basa en la aplicación arqueológica de la analogía, método de análisis que permite especificar cuán similares o diferentes son los procesos que se comparan (Morgado y Baena 2011).

El marco teórico del proceso tecnológico ha sido la cadena operativa (Pelegrin et al. 1988; Karlin et al. 1991; Sellet 1993; Bleed 2002). Este concepto, basado en métodos de investigación de la etnología tecno-económica, y aplicado mayormente a la producción lítica tallada, puede hacerse extensivo a cualquier proceso tecnológico, pues define la ordenación secuencial de las técnicas empleadas en la elaboración de un útil, desde la materia prima en bruto hasta su abandono. En el objeto metálico estudiado, la cadena operativa se muestra a partir de la fíbula mejor conservada (Fig. 2: IIc), haciendo referencia a las similitudes o disimilitudes observadas en las otras piezas del conjunto.

\section{LA MANUFACTURA DE LAS FÍBULAS ARCAICAS "TIPO MONACHIL"}

La sencilla apariencia que puede transmitir la observación superficial directa de las fíbulas oculta objetos complejos. Su elaboración a partir de un elemento simple, como una varilla o un alambre de bronce o cobre, resulta de aplicar determinadas técnicas que se han podido reconstruir y ordenar de forma seriada. A continuación, describimos cada fase de la cadena operativa de la manufactura, aludiendo a las huellas superficiales observadas en las piezas y a la relación secuencial entre ellas. 
Las preformas: las fíbulas son artefactos compuestos. Su elaboración se inicia a partir de un trozo de metal alargado, que puede obtenerse mediante diferentes procedimientos. Pero la identificación del tipo de soporte es complicada. En el conjunto estudiado se han definido dos: una varilla rectangular (Fig. 2: IIc) y un alambre circular (Fig. 2: IIa.1, IIa.2, IIb). La utilización del alambre, o "alambre estirado", ha sido planteada, especialmente por S. Rovira (1987), pero, ¿cómo se elabora un alambre circular de bronce? La solución más sencilla es obtenerlo en un molde mediante fundición. También cabe cortar un trozo de varilla de una placa que, por limado o abrasión, se transforma en un alambre circular (Fig. 4: 4). Discernir entre estos procedimientos ha sido imposible en el conjunto estudiado, pero las secciones de algunas piezas nos permiten afir-


Fig. 4. Esquema del proceso de manufacturación de una fíbula de codo de "tipo Monachil", a partir del modelo de Las Muelas (Alamedilla, Granada): preformas (1-2); preparación de la mortaja (3); realización del resorte (4); Afilado de la aguja (5); doblado del codo y de la mortaja (6); comprobación dimensional de la posición centrada del codo (7). mar que algunas se elaboraron a partir de un alambre circular (Fig. 5: 1, 4 y 3). Sin embargo, la utilización de una varilla rectangular también se ha podido comprobar en la fíbula mejor conservada $\mathrm{y}$, en nuestra propuesta, más arcaica (Fig. 2: IIc). Las huellas en su cara A sugieren que se trata de una varilla recortada de una placa de mayores dimensiones (Fig. 4: 1 y 2). Una incisión longitudinal cortó la barra, desgajada tras un trabajo de flexión, como muestra la rebaba de metal que el limado no pudo eliminar (Fig. 5: 2 y 4). El pulido con limado parece anterior al proceso de deformación plástica, porque si fuera posterior se habrían suprimido fácilmente esos defectos superficiales. Por ejemplo, en la zona del bucle se observa que el interior del alambre está pulido, cuando en esa posición final no parece posible introducir una lima.

Pie o mortaja: se configura en la primera fase de la manufactura (Fig. 4: 3) con técnicas de deformación plástica por forja, o combinándola con ciclos de recocido. Estas técnicas se basan en propiedades mecánicas del metal como la maleabilidad y la ductilidad. Un martillo configura la forma alargada y oblonga del pie. Sus impactos continuos generan huellas fácilmente reconocibles en la superficie del metal como depresiones y ondulaciones (Fig. 6: 6). La técnica empleada, para elaborar las fíbulas que conservan las mortajas (Fig. 2: IIa.1, IIa.2 y IIc), ha sido siempre el martilleado de la preforma (Fig. 6: 4).

Resorte: tiene una cierta funcionalidad móvil, ya que es la parte mecánica que facilita que la aguja entre y salga de la mortaja con un ligero movimiento. La maleabilidad del metal permite este cambio de posición, sin alterar sustancialmente la forma. Las espiras se realizaban con ayuda de un eje sobre el que la varilla o alambre se enrollaba sobre sí mismo, hasta formar el bucle o muelle deseado (Fig. 4: 4). La torsión del metal sobre ese eje producía fisuras superficiales en las partes curvas del resorte. Ello indica que, en ocasiones, se superaba el umbral de ductilidad (Fig. 4: 2 y 1). El martilleado, para configurar la morfología fusiforme de los brazos, también debió llevarse a cabo tras elaborar el resorte (Fig. 5: 3 y 2).

Aguja: es la última parte de la secuencia funcional. Se elaboraba, mediante el aguzamiento progresivo del diámetro de la varilla o del alambre, hasta adquirir forma de aguja. Es complicado reconocer la técnica empleada. El análisis visual 

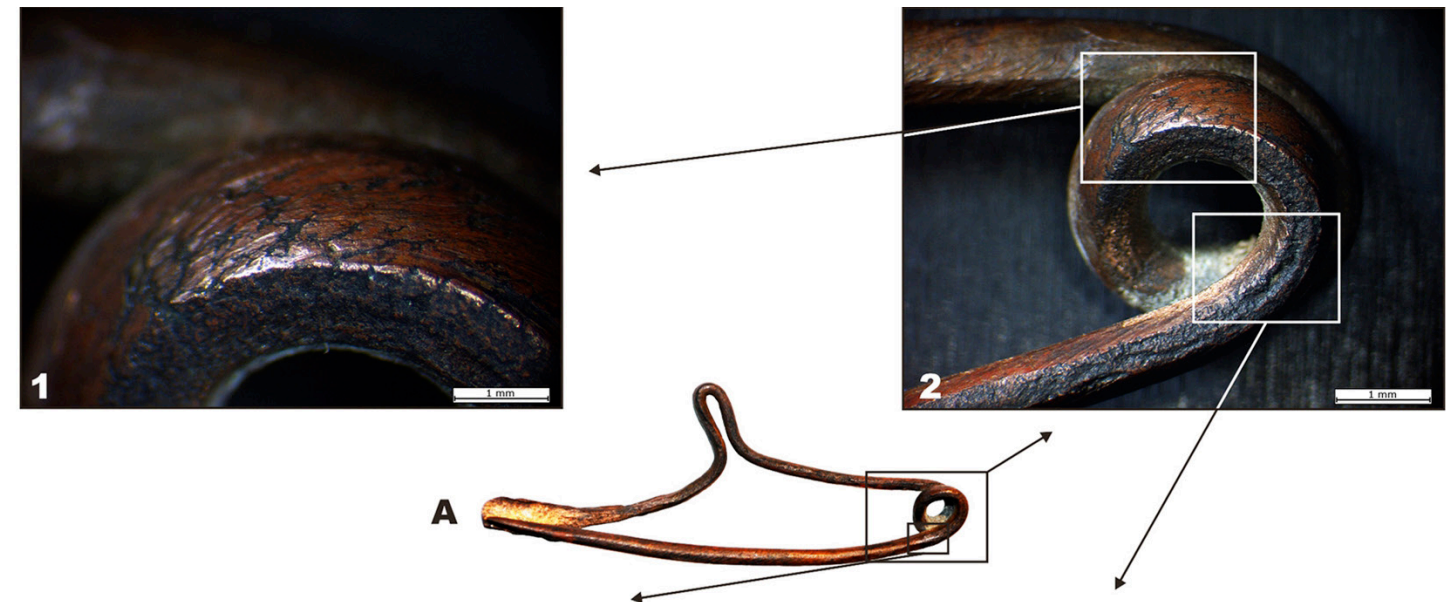

A


B
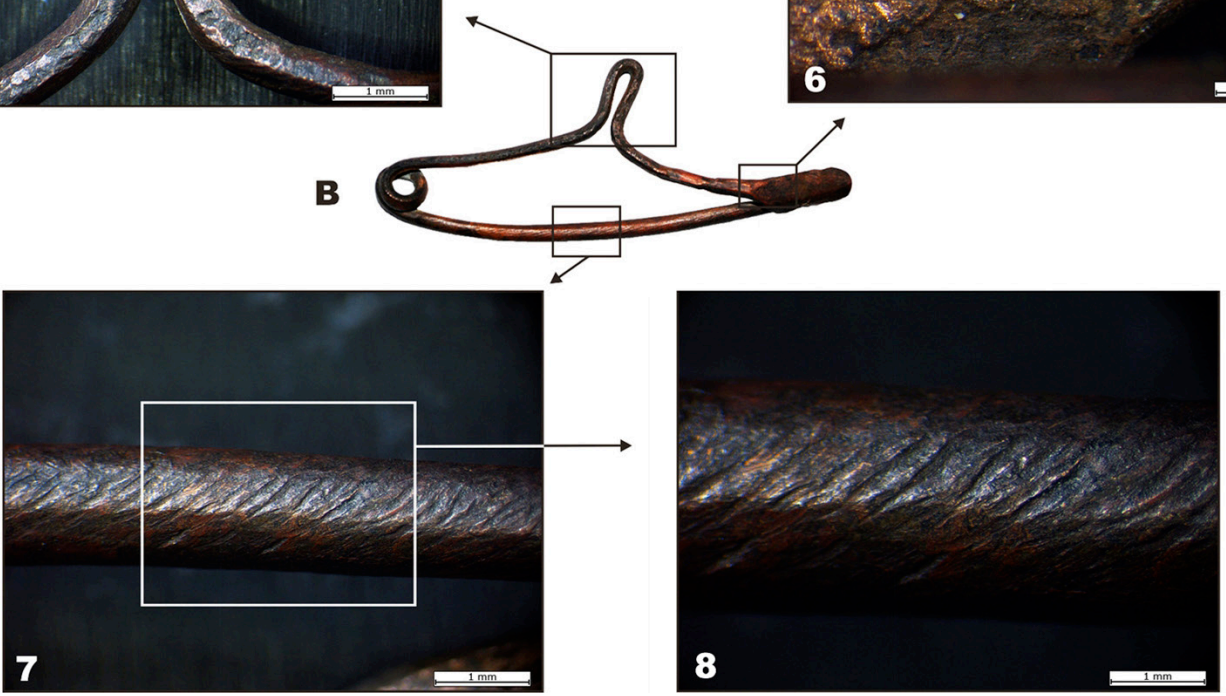

Fig. 5. Trazas arqueológicas de manufacturación (I). Inflexión de la varilla en el codo (1); martilleado en el arranque de los brazos junto al resorte (2-3); detalle de una mortaja, producto del martilleado de la varilla (4). 

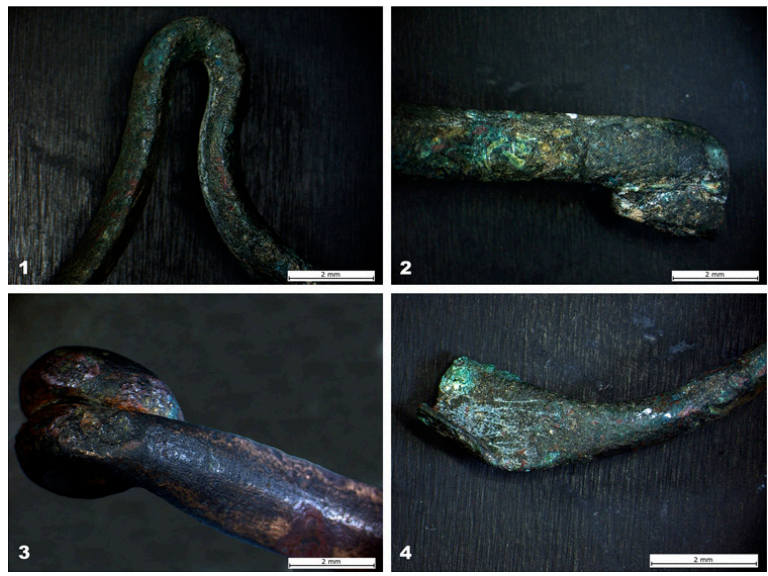

Fig. 6. Fíbula de las Muelas (Alamedilla, Granada) (II): trazas arqueológicas de manufacturación y situación de las mismas (A-B): fracturas por torsión en el resorte (1 y 2); restos de limado en el arranque de la aguja (3); rebaba residual de la obtención de la varilla (4); detalle del codo con la inflexión de la varilla (5); evidencias de martilleado sobre la mortaja (6); estrías de limaduras sobre la aguja (7 y 8). de la superficie de las agujas puso de manifiesto el uso de una herramienta dentada, que eliminaba el metal como una lima actual. Las trazas son estrías de fondo cóncavo distribuidas de forma regular y uniforme (Fig. 5: 7 y 8). La falta de referentes arqueológicos sobre este tipo de herramientas en la Edad del Bronce justificó la realización de pruebas experimentales para la contrastación arqueológica de ese tipo de huellas. Como elementos abrasivos sobre una placa de cobre puro se aplicaron limas para metal de diversos granulados (Fig. 7: 1 y 2), calcarenitas de grano grueso (Fig. 7: 3) y arenisca de grano fino (Fig. 7: 4). La observación con lupa binocular muestra una clara concordancia entre las huellas dejadas por las limas actuales (Fig. 7: 1 y 2) y las arqueológicas (Fig. 6: 7 y 8). Las diferencias observadas, entre las trazas resultantes de las piedras con capacidad abrasiva y las limas, son nítidas. Estas últimas eliminan el metal dejando surcos profundos y regulares (Fig. 7: 1 y 2), mientras que los abrasivos, en vez de suprimirlo, lo arrastran de modo anárquico, formando rebabas en los bordes

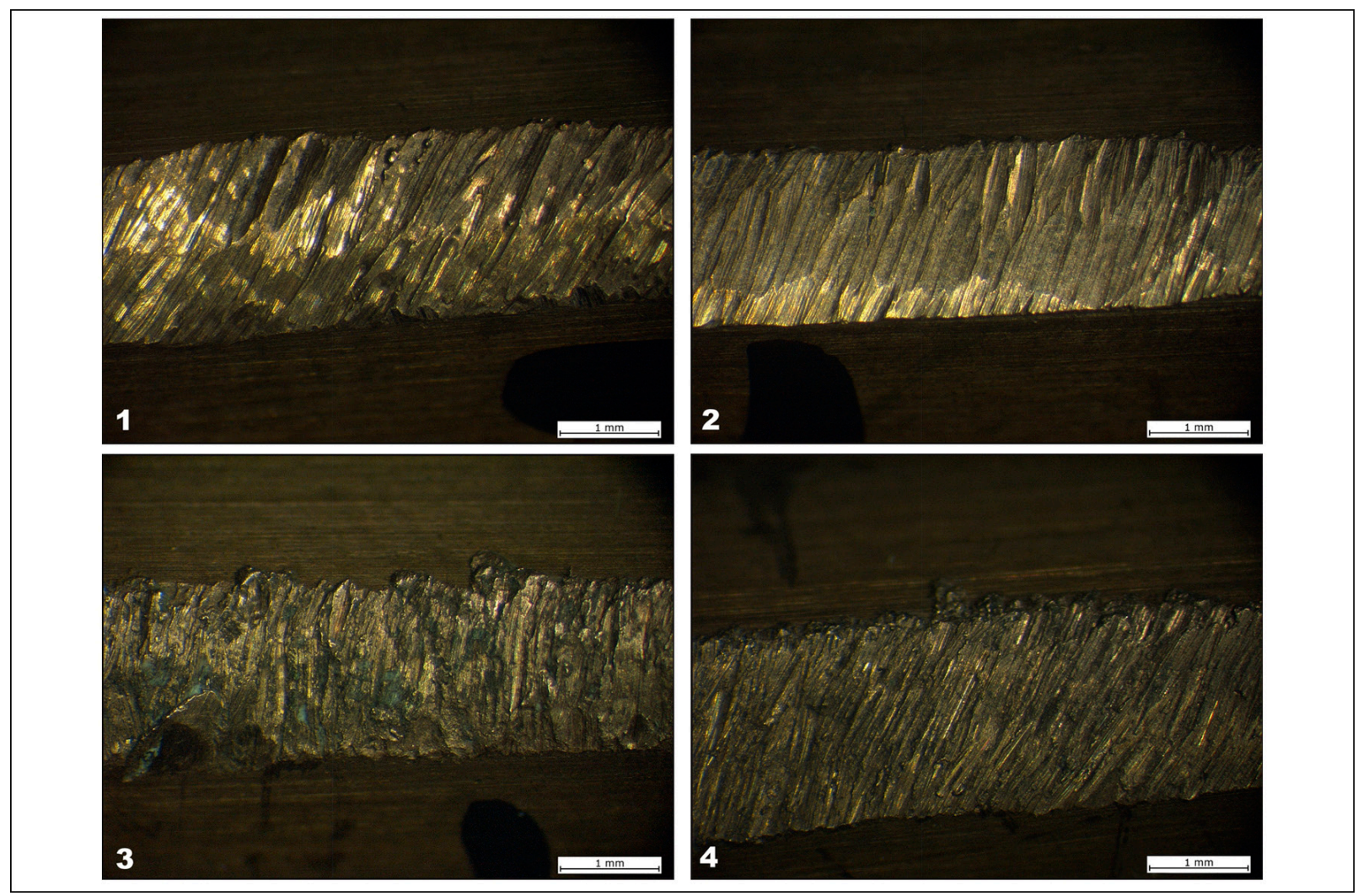

Fig. 7. Trazas experimentales sobre placa de cobre puro: limas de granulado variable (1-2), calcarenita de grano grueso (3) y arenisca de grano fino (4). Observación macroscópica y con lupa binocular entre 0 y 80 aumentos. 
(Fig. 7: 3 y 4). Con esto no estamos planteando que hubiera limas como las actuales en el Bronce Final, pero sí algún utensilio de similares características, capaz de dejar parecidas huellas al usarse. La cuestión habrá de comprobarse o reconocerse en futuras investigaciones, especialmente a partir de análisis más intensivos de útiles similares o de diferente tipología del Bronce Final.

El codo: es una de las partes más características de las fíbulas antiguas, como en el "tipo Monachil", siendo un elemento decorativo, no funcional. Se hacía incurvando, hasta alcanzar $1800^{\circ}$, el alambre o la varilla por la parte central del puente (Figs. 6: 1 y 5: 5). Esa disposición es de gran trascendencia tipológica: en cuatro piezas el codo aparece vertical y centrado respecto de los brazos y, solo en la IIc, inclinado hacia el brazo izquierdo (Fig. 2). Según el estudio métrico, esa peculiaridad se debió a un "fallo" del artesano, no a una característica tipológica. El codo siempre se elaboraba en la última fase del proceso de manufactura. Su conjunción con el puente tenía que estar muy equilibrada, para que coincidiera con el tamaño de la aguja y esta pudiera recogerse en la mortaja, sin excederla ni quedar corta. $\mathrm{Al}$ configurar un puente demasiado largo en la fíbula IIc, la mortaja sobrepasaba el tamaño real de la aguja. La sencilla solución del artesano a este problema funcional fue flexionar e inclinar el codo hacia su izquierda, para reducir el tamaño del brazo y la mortaja, ajustándolo a la medida original de la aguja (Fig. 4: 7).

Las decoraciones: solo aparecen en la IIa.1 (Fig. 2). En cada brazo se realizaron tres franjas rayadas, incisas con algún útil afilado o abrasivo. $\mathrm{La}$ distribución asimétrica de las franjas, y su acabado, podrían indicar que se añadieron después de elaborar la fíbula.
De forma sintética, la cadena operativa de las fíbulas arcaicas "tipo Monachil" comprende seis fases: 1) preformas sobre una varilla rectangular o un alambre circular; 2) configuración de la mortaja mediante martilleado; 3 ) elaboración del resorte; 4) afilado de la aguja por abrasión o limado; 5) realización del codo; 6) decoraciones mediante incisiones aleatorias.

Indicamos para finalizar este apartado que, según el análisis de tan singular conjunto de fíbulas, podemos reconocer una evidente similitud tecnológica, con leves variaciones, entre las formas más antiguas del "tipo Monachil". A falta de otros acercamientos, este estudio debe servir de referencia para generar, en futuros trabajos, explicaciones tecno-tipológicas y de otro tipo que permitan un conocimiento más exhaustivo de la variabilidad de las fíbulas del Bronce Final en la Península Ibérica.

\section{METALURGIA}

Se ha analizado la composición de cinco fíbulas de Monachil, Canto Tortoso, Las Muelas y el Cerro de la Mora. Los resultados obtenidos en esta última, afectados por su pésimo estado de conservación, no son representativos de la aleación original (bronce) por lo que no se han incluido en la tabla 2.

Los análisis de los ejemplares procedentes de Canto Tortoso y Las Muelas se han complementado con otros por Microscopio Electrónico de Barrido (MEB) y Espectrometría de Masas con fuente de Plasma de Acoplamiento Inductivo $(M C-I C P-M S)$ Los análisis del MEB se han realizado en el Microlab del Instituto de Historia del CSIC (Madrid) con un Microscopio Electrónico

\begin{tabular}{|l|c|c|c|c|c|c|c|c|c|}
\hline \multicolumn{1}{|c|}{ Fíbula } & $\mathbf{F e}$ & $\mathbf{N i}$ & $\mathbf{C u}$ & $\mathbf{Z n}$ & $\mathbf{A s}$ & $\mathbf{A g}$ & $\mathbf{S n}$ & $\mathbf{S b}$ & $\mathbf{P b}$ \\
\hline Monachil 1(ICP) & 0,012 & 0,106 & 91,2 & 0,008 & 0,21 & 0,046 & 6,86 & 0,06 & 0,088 \\
\hline Monachil 2 MEB & - & - & 93,5 & - & nd & - & 6,3 & - & nd \\
\hline Canto Tortoso & & & & & & & & & \\
MEB & - & - & 93,5 & - & & - & 6,40 & - & nd \\
ICP & 0,011 & 0,064 & 92,7 & 0,001 & & 0,050 & 6,43 & - & 0,49 \\
\hline Las Muelas & & - & 98,5 & - & 1,5 & - & 0,002 & - & nd \\
MEB & 0,22 & 0,001 & 96,7 & 0,028 & 3,0 & 0,008 & & 0,004 & \\
ICP & 0.004 \\
\hline
\end{tabular}

Tab. 2. Análisis elemental de las fíbulas “tipo Monachil”. Valores expresados en \% en peso. Microscopio Electrónico de Barrido (MEB); Espectrometría de Masas con fuente de Plasma de Acoplamiento Inductivo (ICP). 
de Barrido de presión variable (VP-SEM) Hitachi S3400 n, type II, mediante un microanálisis por dispersión de energías de rayos-X (EDX) acoplado. Los análisis $M C-I C P-M S$ se han efectuado en el Servicio de Geocronología de la Universidad del País Vasco. Estos precisan mejor los elementos minoritarios que no pueden detectarse en el MEB y, en especial, permiten averiguar la presencia/ausencia de estaño en la fíbula de Las Muelas, cuyo resultado inicial en el MEB fue cobre con arsénico. Los análisis ICP han confirmado la ausencia de estaño (25 ppm), reduciendo las opciones de que fuera un metal reciclado donde suelen quedar siempre restos de estaño (Montero 2008: 502-503). En consecuencia, la fíbula se elaboró de manera intencionada con cobre sin alear y sobre metal nuevo.

Consideramos que, por tecnología, tipo de metal, contexto arqueológico y por las altas cronologías de este subgrupo, la fíbula de Las Muelas es una de las más antiguas del Mediterráneo Occidental. Su manufactura en cobre sin estaño sería aún propia de los últimos momentos argáricos. No se conoce nada similar entre las fíbulas de codo del Bronce Final de la Península Ibérica, ni tampoco de Italia (Hook 2007; Giumlia-Mair et al. 2010). De igual forma, las medias porcentuales de los análisis realizados por Craddock (1976), en fíbulas griegas del Protogeométrico y Geométrico, indican porcentajes medios de estaño (Sn 7,66\% y 8,32\%) alejados de los resultados obtenidos en el "tipo Monachil" antiguo (A).

Las fíbulas de Monachil 2, Canto Tortoso y Las Muelas tienen una aleación de bronce binario con porcentajes medio-bajos de estaño en torno al 6-7\%, muy similares a los de otras fíbulas de codo antiguas del "tipo Huelva" y "Monachil", principalmente de Andalucía Oriental (Carrasco et al. 1999). El arsénico (As) es el oligoelemento mayoritario.

Las muestras para los análisis de isótopos de plomo de esas tres fíbulas (Tab. 3) se extrajeron mediante limadura del metal, empleándose limas diferentes para cada una. La técnica de alta precisión $(M C-I C P-M S)$ escogida es necesaria para poder conseguir una información comparable a análisis previos (Santos et al. 2004), minimizando los márgenes de error y de interpretación en la asignación de campos isotópicos con base geológica.

Los resultados obtenidos (Fig. 8) parecen indicar un origen diferente para cada fíbula, aunque en estos momentos es difícil proponer una procedencia más exacta, principalmente por faltar datos de las mineralizaciones de cobre de la propia provincia de Granada para la comparación. Ahora mismo, con la información geológica disponible, solo podemos apuntar una relación de la fíbula Monachil 2 con la mineralización de la Faja Pirítica de Huelva y nos parece dudosa. Hay elementos en esta comparación que no acaban de encajar perfectamente, sugiriendo que la signatura isotópica pueda resultar de una mezcla de procedencias diferentes. Este aspecto debe valorarse en el futuro, dada la característica composición de bronce pobre que esta fíbula presenta en el análisis elemental. Lo que sí se puede afirmar es



Fig. 8. Gráfica de procedencia de las fíbulas granadinas estudiadas, en cuanto a las evidencias isotópicas de plomo contrastadas en la Península Ibérica.

\begin{tabular}{|c|c|c|c|c|c|}
\hline Yacimiento & $\begin{array}{c}\mathbf{2 0 8 P b} \\
\mathbf{2 0 6} \mathbf{P b}\end{array}$ & $\begin{array}{c}\mathbf{2 0 7 P b} / \\
\mathbf{2 0 6 P b}\end{array}$ & $\begin{array}{c}\mathbf{2 0 6} \mathbf{P b} / \\
\mathbf{2 0 4 P b}\end{array}$ & $\begin{array}{c}\mathbf{2 0 7 P b} \\
\mathbf{2 0 4} \mathbf{P b}\end{array}$ & $\begin{array}{c}\mathbf{2 0 8 P b} / \\
\mathbf{2 0 4} \mathbf{P b}\end{array}$ \\
\hline Canto Tortoso & 2,08704 & 0,84164 & 18,6304 & 15,680 & 38,882 \\
\hline Las Muelas & 2,10166 & 0,85551 & 18,2969 & 15,653 & 38,454 \\
\hline Monachil 2 & 2,10013 & 0,85779 & 18,2183 & 15,627 & 38,261 \\
\hline
\end{tabular}

Tab. 3. Análisis de isótopos de plomo por Espectrometría de Masas con fuente de Plasma de Acoplamiento Inductivo $(M C-I C P-M S)$ de las fíbulas de codo "tipo Monachil", procedentes de la provincia de Granada estudiadas.

Trab. prehist., 71, N. ${ }^{\circ}$, enero-junio 2014, pp. 95-112, ISSN: 0082-5638

doi: $10.3989 /$ tp.2014.12126 
que el metal de las fíbulas no procede de las minas del Valle de la Alcudia en Ciudad Real, ni de las de Linares en Jaén, ni del área de Los Pedroches en Córdoba, ni de las minas de Murcia y Almería, hasta ahora caracterizadas.

En este último sentido, existen otras muchas referencias sobre recopilación de datos geológicos de la Península Ibérica, cuya relación y peculiaridades pueden contrastarse en otro sitio (Bartelheim et al. 2012). Un amplio estudio que llega a considerar cerca de ochocientas muestras, incluyendo otras inéditas que se han obtenido de proyectos de investigación vigentes y en los que existe una directa responsabilidad de uno de nosotros (I. Montero).

\section{CRONOLOGÍA Y CONCLUSIONES}

En general, las tradicionalmente denominadas "fíbulas sículas" de la Península Ibérica no han tenido un tratamiento específico y, menos aún, cronológico, englobándose de modo sesgado entre las del tipo antiguo, con o sin codo. Su cronología ha dependido de las de "tipo Huelva" y de las alternativas experimentadas por la investigación sobre los bronces de la Ría de Huelva a lo largo de los años. Los modelos interpretativos de Almagro Basch sobre la dependencia de estas fíbulas lisas respecto de las sículas italianas, brillantes en su momento, se han mantenido incomprensiblemente sin alterar durante más de setenta años. A ello contribuyó el que no se comprobara la reconstrucción de la fíbula lisa de la Ría de Huelva, cuyo codo descentrado dio credibilidad a unas aparentes relaciones con fíbulas similares de ambientes sicilianos. Además, se creó una posterior y consistente literatura sobre la llegada de estos imperdibles a la Península Ibérica a través del comercio, o incluso por la arribada de poblaciones procedentes del Mediterráneo Central, especialmente de Sicilia y del sur de Italia.

No vamos a incidir sobre las investigaciones, por otra parte escasas, de este tema. La trayectoria expuesta puede seguirse en ciertos trabajos de C. Blasco (1987), M. Ruiz-Gálvez (1995) y, más recientemente, de S. Celestino $(2001,2008)$ y M. Torres $(1999,2002,2008 a, 2008 b, 2012)$. En realidad, el referente en cualquier oportunidad al publicar algún hallazgo fibular de codo, contextualizado o no, ha sido siempre, sin excesivos problemas, el "modelo sículo" de Almagro Basch y el horizonte siciliano de Pantalica II, e incluso III, de la Protohistoria italiana; todo, para argumentar las cronologías y orígenes extra-peninsulares de los imperdibles.

En trabajos directos recientes hemos ido exponiendo la dificultad de seguir manteniendo, esencialmente por tipología y cronología, el modelo sustentado sobre el origen sículo de las fíbulas peninsulares de codo "tipo Monachil" (Carrasco et al. 2012, 2013). Estudios previos de investigadores italianos como Eles Masi (1986), M. Turco (2000) y especialmente F. Lo Schiavo (2010) han fortalecido, en cierta manera, nuestras hipótesis al respecto. Sin embargo, no los tomamos como definitivos, especialmente en lo referente a las imprecisas dataciones de las fíbulas, cuyo parentesco con las españolas se ha forzado. Valoramos que documentan de modo exhaustivo la globalidad de las fíbulas italianas, lo que ha permitido compararlas con las españolas consideradas similares.

Sobrepasan la decena de millar las fíbulas procedentes de Italia, de las que resultan de especial interés las documentadas en su parte meridional y Sicilia, que hemos visualizado y contrastado exhaustivamente. En principio y en síntesis, reafirman lo ya publicado respecto de los ejemplares descritos de la fase antigua del "tipo Monachil" (Monachil, Las Muelas, Canto Tortoso y Cerro de la Mora): sin que haya, durante el Bronce Reciente y Final en toda Italia, un solo modelo o tipo para su entronque tipo-cronológico, ni tradición alguna sobre estos imperdibles. Huelga, pues, toda especulación que pudiésemos efectuar sobre similitudes. Otras consideraciones tampoco tendrían más finalidad que adentrarnos en lo meramente erudito e historiográfico.

Grosso modo, hemos fechado nuestro grupo A entre los siglos XIII-XI a.C. Esta cronología, muy amplia y poco precisa, podría justificarse por las características morfométricas y tecnológicas de las fíbulas que lo componen, al margen de lo aportado por nuestra propia experiencia sobre este tipo de artilugios paradigmáticos del final de la Prehistoria Reciente. Pero también podemos ofrecer una datación absoluta para el ejemplar del Cerro de la Mora que, aunque problemática por su amplio intervalo cronológico, está bien avalada por el contexto arqueológico en el que se exhumó. Aunque antes de discutir su importancia, valoraremos sucintamente las escasas dataciones absolutas que en el ámbito peninsular han sido relacionadas con fíbulas de codo antiguas. 
En principio, son las recién publicadas del yacimiento de Las Lunas en Yuncler, Toledo (Urbina y García 2010, 2013), las que fechan el contexto de un depósito broncíneo con un extraordinario ejemplar de codo descentrado, junto a las problemáticas de la Ría de Huelva (Almagro-Gorbea 1978), San Román de Hornija (Delibes 1978) y Cerro de la Miel (Carrasco et al. 1985; Carrasco et al. 1987), relacionadas con ejemplares del "tipo Huelva". Esta escasa base de fechaciones no ha sido óbice para que la investigación peninsular haya montado en los últimos años un entramado cronológico en el que ha tenido cabida, de manera forzada, todo el conjunto fibular peninsular. No se han discriminado tipos, ni diferencias morfo-tipológicas que, evidentemente, pueden responder en origen a múltiples tradiciones y cronologías. Incluso se han elaborado mapas de distribución de lo más variopinto, dentro de un gran confusionismo. Pero, además, se ha propuesto la posible llegada de estas fíbulas desde el Mediterráneo central, o a través de intermediarios desde otras áreas geográficas más alejadas del Mediterráneo oriental. Las mismas dataciones absolutas del depósito de la Ría de Huelva han sido envejecidas continua y reiteradamente sin ningún reparo ni, menos aún, estrictos y fiables argumentos novedosos. Así, sus iniciales cronologías absolutas del siglo IX a.C., que databan la madera conservada en algunos regatones del heterogéneo depósito, se generalizaron al resto de los bronces sin tener muy en cuenta su posible cronología de origen. Entre ellos estaban las fíbulas, clasificadas según paralelos mediterráneos y extra-mediterráneos de la más diversa etiología, pero cuyas cronologías tampoco eran más nítidas que las de los ejemplares que pretendían precisar.

Posteriormente, ese mismo proceso de envejecimiento afectaría a otros ejemplares peninsulares. Lo mismo se databa un tipo ad occhio que un "tipo Huelva" o de codo descentrado, etc., importando solo su mejor adecuación a los marcos temporales utilizados ad usum privatum. Mediante esta imparable subida temporal, sin excesivos argumentos fiables se llegó al siglo $\mathrm{X}$ e incluso al XI a.C., cuando ya no se databan las fíbulas "tipo Huelva", o incluso las sículo lisas o "tipo Monachil", documentadas en la Ría de Huelva, sino una amplia gama de diferenciadas tipologías y desarrollos de escasas y dudosas relaciones en origen y sin contextos precisados. En este ascenso de las cronologías de las fíbulas de codo, especialmente las del "tipo Huelva", han sido determinantes las dataciones absolutas obtenidas en San Román de Hornija y Cerro de la Miel, donde existían trasfondos arqueológicos, pero cuya amplitud cronológica fue objeto de críticas poco justificadas en su momento.

Todo este galimatías cronológico y tipológico de las fíbulas de codo españolas se sustentó, con mayor o menor éxito, en hallazgos realizados en otros ámbitos próximos o lejanos del Mediterráneo. Los relativos a las del "tipo Huelva", en cierta forma ya han sido tratados (Carrasco y Pachón 2006a, 2006b, 2006c). Las de "tipo Monachil", objeto de este estudio, solo lo han sido de forma tangencial. Por lo que debe acentuarse su originalidad e independencia en origen y su relación con las que situamos en la fase antigua A de las denominadas "sículas". Los posteriores desarrollos o evoluciones del "tipo Monachil", grupos B, C y D (Fig. 1), podrían admitir alguna relación aislada con las fíbulas sicilianas. Pero, en cualquier caso, no implicaría que estas fueran su modelo. Por su escasez, rareza y falta de tradición no conformarían ningún grupo claramente definido y cuentan con una ambigua cronología relativamente tardía.

La datación C14 que vamos a considerar, $2990 \pm 90$ BP (González et al. 1987), fue obtenida sobre carbón extraído del fondo de una cabaña circular del Bronce Final antiguo con numerosas cerámicas, excavada en 1986 en la extensa secuencia del Cerro de la Mora. La tabla 4 muestra los resultados de la calibración con el Programa Calib. 6.1.0 (Reimer et al. 2009). El intervalo de calibración es elevado, en especial por su alta desviación estándar ( \pm 90 años), propia de las dataciones obtenidas en la década de 1980 por el Laboratorio de C14 de la Universidad de Granada (UGRA). Lo mismo ocurre con las otras trece muestras analizadas de esa secuencia, aunque todas ellas son progresivas y de una gran coherencia. Esa circunstancia intrínseca a las dataciones no nos impide considerar aceptable la cronología de la segunda mitad del siglo XIII a.C., avalada especialmente por el contexto arqueológico fiable del Bronce Final I, bien estratificado del Cerro de la Mora. La data C14 mencionada, aplicable a la fíbula documentada en el yacimiento, marca un hito cronológico entre los imperdibles de codo, sea cual sea su tipo, de la Península Ibérica. 


\begin{tabular}{|c|c|c|c|c|}
\hline LAB. & Fecha BP & $\begin{array}{c}\text { Intersección } \\
\text { curva calibración }\end{array}$ & $\mathbf{1} \boldsymbol{\sigma}(\mathbf{6 8 \%}):$ & $\mathbf{2} \boldsymbol{\sigma}(\mathbf{9 9 , 9 5 \% ) :}$ \\
\hline \multirow{2}{*}{ UGRA-263 } & $2990 \pm 90$ & \multirow{2}{*}{$1261 \mathrm{BC}$} & $1382-1334 \mathrm{BC}(16 \%)$ & $1432-976(99,95 \%)$ \\
\cline { 4 - 5 } & & $\begin{array}{c}1324-1115 \mathrm{BC}(84 \%) \\
(57,12 \% \text { del total })\end{array}$ & $951-950(0,05 \%)$ \\
\hline
\end{tabular}

Tab. 4. Datación sobre carbón, extraído del fondo de una cabaña del Bronce Final antiguo del Cerro de la Mora (muestra CM/86/CV-B) (González et al. 1987) calibrada con el Programa Calib. 6.1.0 (Reimer et al. 2009).

Hemos adelantado de forma sucinta, que nuestras fíbulas antiguas "tipo Monachil", siglos XIIIXI a.C., no tienen similitudes morfo-técnicas con las conocidas de esta cronología en otros ambientes mediterráneos. Existe una gran dificultad para sistematizar la multitud de fases culturales y dataciones absolutas y relativas del final de la Prehistoria italiana, pero puede corresponder - $\mathrm{O}$ acoger- lo que se denomina generalmente Bronce Reciente (BR), 1. ${ }^{\circ}$ Orizzonte dei ripostigli y fase Pantalica I del Bronce sículo, entre el siglo XIII y la primera mitad del XI a.C. Todas las fíbulas antiguas que se constatan entonces, en la Italia continental e insular, son variantes del tipo violín y posteriormente de arco simple. Sus tipologías son muy diferentes de las antiguas de la fase A del "tipo Monachil" de la Península Ibérica y sin visible relación genética entre sí.

Podríamos adjudicar a ese tipo fibular, sobre todo por su arcaica morfo-tipología y su alta cronología, mayor antigüedad que al resto de fíbulas de codo documentadas en la Península Ibérica. La única excepción podría ser la fíbula de arco de violín, publicada por Delibes (1981), conocida por un dibujo y cuya procedencia de El Berrueco no es segura. De ser cierto su origen, y dado su carácter único peninsular, podría justificarse su presencia por algún comercio desconocido, antiguo o moderno, pero sin relación con la procedencia de las antiguas fíbulas de "tipo Monachil". Estas últimas podrían completar el espacio entre los siglos XIII-XII a.C., poco conocido en la Península Ibérica y que no rellenan fíbulas como las de "tipo Huelva", ad occhio, codo descentrado, etc., que, en los ámbitos italianos y orientales, sí cubren las variantes fibulares de violín y arco simple.

En el sur de Italia y Sicilia, la mayoría de las fíbulas fechadas desde finales del siglo XI y siglo $\mathrm{X}$ a.C. son de codo o bucle descentrado, al contrario de lo que sucede con los ejemplares peninsulares tardíos, al margen de tener una cro- nología similar, o incluso más tardía que ellos. Corresponden al Bronce Final I-2, Fase Pantalica II del Bronce sículo y Pantalica III/I Hierro del siglo IX a.C. y, en cierta forma, pueden relacionarse con formas más tardías del "tipo Monachil". Asimismo, las escasas fíbulas italianas con codo centrado, tipos 290.1 y 290.2 de Lo Schiavo (2010: 603), no han sido bien interpretadas por la autora en relación con las españolas, por utilizar fuentes de segunda mano y una documentación limitada sobre las fíbulas de la Ría de Huelva (Ruiz-Gálvez 1995). La investigadora italiana, al comparar con ellas los motivos decorativos de sus fíbulas sículas, indica que la documentación primaria de Almagro Basch (1940a) sobre las fíbulas onubenses es insuficiente. Salva solo una de procedencia desconocida de la Meseta, conservada en el Museo de Barcelona, que parece confundir con ellas. Menciona la decoración incisa de las onubenses para relacionarlas con las de Cassibile, cuando no existe una relación tipológica nítida con las de "Huelva": las molduraciones de los brazos del puente de las hispanas faltan en los ejemplares sicilianos y estos, a su vez, tienen siempre codos claramente descentrados. Quizá, si Lo Schiavo hubiese consultado los trabajos originales de Almagro (1940a, 1940b), habría advertido que la única fíbula que puede tener alguna relación en origen con las sicilianas sería su famosa sícula de brazos "amorcillados", cuya fina decoración incisa tampoco fue apreciada por Ruiz-Gálvez. De todas maneras, ninguna de estas fíbulas sicilianas guardaría una directa relación con las del "tipo Huelva".

Sin embargo, en las fíbulas 5279 (tipo 290.1) y 5279B (tipo 290.2) de Lo Schiavo (2010: 603) constatamos ciertas similitudes con otras tardías del "tipo Monachil". La primera, lisa y de codo centrado, se localizó en la tumba 8 de la necrópolis de Cassibile, con una cronología ambigua del Bronce Final 3, de fines de la fase Pantalica II, entre los siglos X-IX a.C. La segunda, ya re- 
ferida (Carrasco et al. 2012, 2013), es una pequeña fíbula sin mortaja, que tendría el codo centrado y el puente decorado con finos trazos incisos paralelos sobre el puente. Es muy similar a la de El Coronil (Sevilla) y tiene evidentes relaciones formales con el ejemplar liso de la Ría de Huelva y con otro semejante del Cerro de la Agujetas en Pinos Puente (Granada). La pieza sícula procede de un depósito de bronces de Castelluccio (Ragusa), fechado en el III Orizzonte dei ripostigli (BF 3-I Fe IA) que se incluiría en la Fase Pantalica III, básicamente del siglo IX a.C. Estos imperdibles difieren de las demás fíbulas de puente asimétrico italianas, pero son tan escasos que no permiten configurar un tipo, existiendo más ejemplares en la Península Ibérica que en Sicilia para definirlo.

Una fíbula de la tumba 54 de Cassibile, asignada sin precisión a Pantalica II (Lo Schiavo 2010: 745) y la I Edad del Hierro, entre los siglos IX/VIII a.C. (Turco 2000), guarda una cierta similitud con la antigua fíbula de Las Muelas por el perfil del puente, aunque el codo es más asimétrico. En cambio, sus mayores dimensiones y su elaboración, sobre una amplia pletina de 9/10 $\mathrm{mm}$ de anchura y $3 \mathrm{~mm}$ de grosor (Lo Schiavo 2010: tavola 526, n. ${ }^{\circ}$ 6697), la diferencian ostensiblemente de la granadina.

En resumen, el actual registro fibular antiguo no justifica que las denominadas fíbulas lisas arcaicas del "tipo Monachil" llegaran a la Península Ibérica en relación con poblaciones, comercio, conexiones, etc., desde el sur de Italia y Sicilia u otros ambientes conectados con ellas. Es posible que, desde la segunda mitad del siglo $\mathrm{X}$ y en el IX a.C., existiera cierto nexo entre la península y el sur de Italia por la presencia en ambas de formas fibulares, más o menos comunes, aunque no totalmente similares, conectadas con tipos diferentes al de "Monachil" o muy evolucionados respecto del mismo. Por ejemplo, la fíbula tardía de puente descentrado y origen desconocido del Servicio de Investigación Prehistórica de Valencia (Almagro 1957, 1966) puede tener alguna relación con alguna de las documentadas en las necrópolis sicilianas de Cassibile o haber sido importada desde esos ámbitos, no suficientemente conocidos, en una fase antigua o como parte de una transacción más moderna. Debe recordarse que todas las fíbulas ad occhio peninsulares tienen el bucle centrado, no así las sicilianas. Además, la cronología de algunas, especialmente las procedentes de Perales del Río (Blasco 1987) y Soto de Tobilla (Quintana y Cruz 1996), podría incluso ser más antigua que la de las propias sicilianas.

En definitiva, comprobamos la escasa o nula relación de las fíbulas de la fase antigua de "tipo Monachil" con las italianas, especialmente con las denominadas sículas. Buscar sus orígenes o paralelos en otras regiones mediterráneas, como las paradigmáticas regiones orientales, nos llevaría, conociendo el registro actual, a conclusiones parecidas. La media docena de fíbulas orientales que podríamos paralelizar con las del "tipo Monachil" también son insuficientes para conformar un tipo, pero no impide reconocer afinidades entre algunas fíbulas de perfil alto en forma de triángulo isósceles y codo centrado, constatadas desde antiguo en Chipre y Palestina, y las antiguas del "tipo Monachil". Sin embargo, cuando estas fíbulas orientales, consideradas arcaicas, se analizan en detalle, se advierten rasgos significativos que las alejan de las peninsulares. Entre ellos están los brazos de puente moldurados y una cronología sensiblemente inferior, atestiguada en las chipriotas de Kourion en la Colección Cesnola, Amathus 243 y 523, antigua de Larnaka, etc., y en las palestinas de Samaria-Sebarte y Megiddo Va, controvertidas y de amplia bibliografía (Carrasco y Pachón 2006c). También, aunque algo alejado de este contexto oriental, el ejemplar liso de Lefkandi, en la isla griega de Euboia (Carrasco y Pachón 2006c), aunque es de perfil bajo y cronología más reciente. Se realizó sobre una amplia pletina de oro con codo centrado, pero recuerda alguna elaboración sícula tardía, como la fíbula de la tumba CS54 de Cugno Spineta de Cassibile (Turco 2000), correspondiente al tipo 369.1 de Lo Schiavo (2010: tavola 526, n. ${ }^{\circ}$ 6697).

El número conocido de fíbulas de este grupo oriental no se ha incrementado en los últimos años, por lo que pueden considerarse piezas aisladas entre los tipos mayoritarios de violín y arco simple con sus múltiples variantes. La ausencia de nuevos hallazgos no ha impedido seguir especulando con la cronología de alguna de las fíbulas conocidas: por ejemplo, la fíbula de Megiddo Va, objeto de innumerables controversias por su dudosa ubicación estratigráfica y problemática cronología. La polémica a este respecto puede ayudar a una mejor comprensión de la fecha adjudicada a las que componen la antigua fase (A) del "tipo Monachil". 
Recientes trabajos sobre la cronología de la Edad del Hierro en el Mediterráneo (Bruins et al. 2011 vs. Fantankil et al. 2011) recogen, comentan y corrigen las nuevas cronologías absolutas de las fíbulas de Megiddo Va, Achziv, Torre Galli, Ría de Huelva, etc. Estas cronologías, tangencialmente sirven para valorar la obtenida en el Cerro de la Mora para el "tipo Monachil". En síntesis, una data absoluta para Megiddo H5 (IVB-VA) del $2817 \pm 23$ BP, apoyada en cuatro dataciones por C14 (Sharon et al. 2007: 36, table 7), aseguran su famosa fíbula hacia la mitad del siglo $\mathrm{X}$ a.C. Otras indagaciones (Plicht et al. 2009), en base a las seis dataciones por C14 del depósito de la Ría de Huelva obtenidas por Almagro Gorbea (1978), sitúan en el $2815 \pm 30$ BP la cronología de su depósito broncíneo y, por ende, de sus fíbulas. Al asignar la misma fecha a la documentada en la tumba 1 de Achziv, se establece un doble paralelismo cronológico: entre el Hierro Antiguo II israelí y los momentos finales del Bronce Final en España y entre las fíbulas de Megiddo Va, Achziv y las onubenses. La argumentación resulta muy coherente sobre el papel, pero olvida que, en Huelva, se fechó la madera conservada en el interior de unos regatones, recogidos entre una gran variedad de objetos, en un conjunto broncíneo abierto de muy dispar tipología y, por supuesto, cronología. En suma, se están paralelizando fechas que corresponden a tipos diferentes: regatones y fíbulas.

Fuimos pioneros al señalar las analogías y posibles relaciones entre la fíbula de Achziv y algunos ejemplares del "tipo Huelva" (Carrasco y Pachón 2006c). En su momento, E. Mazar (2004: fig. 28,1) situaba el ejemplar israelita en el periodo inicial de ocupación de la cámara funeraria donde se localizó: siglo X e inicios del IX a.C. La fecha actual ya comentada, hacia mediados del siglo $\mathrm{X}$, no afecta lo que en su momento expusimos al situarla, por sus características morfométricas y cronológicas, "en una posición avanzada de nuestro desarrollo tipológico, por lo que la datación aportada por la excavación de referencia sería un apoyo de indudable valor para nuestros planteamientos, aunque no tanto para el origen del tipo fibular" (Carrasco y Pachón 2006c: 79). Es decir, ya sea de principios del siglo IX o de mediados del $\mathrm{X}$ a.C., no altera nuestra visión de que es una forma evolucionada dentro de nuestra secuencia tipológica del "tipo Huelva".
En cierta forma, Bruins et al. (2011) justifican y documentan las nuevas cronologías absolutas del Hierro Antiguo II, que correlacionan la fachada mediterránea oriental y otros ámbitos de la centro occidental (España, Italia) con fases finales del Bronce Final/Hierro I, asumiendo una cronología similar para las fíbulas orientales de Megiddo VA, Achziv, Samaria, Kourion, Amathus 523, las sicilianas de Tre Canalli y las españolas de la Ría de Huelva. No sabemos a ciencia cierta, si su disposición en la tabla o figura (Bruins et al. 2011: fig 1) implica una secuencia cronológica o tipológica, que iría desde la de Achziv/Megiddo Va hasta las sicilianas de Tre Canalli, pasando por las de Samaria, Ría de Huelva y las chipriotas de Kourion y Amathus 523 y 125. Si fuera así, no reflejaría, a nuestro entender, ninguna realidad arqueológica: difieren en la tipología $y$, probablemente en algunos casos, en la cronología.

En conclusión, estas fíbulas orientales, como las italianas e incluso griegas, no tienen correspondencia cronológica ni tipológica nítida con las de "tipo Monachil" y menos aún, como hemos tratado de exponer, con las más antiguas de su fase A.

\section{BIBLIOGRAFÍA}

Almagro Basch, M. 1940a: "El hallazgo de la Ría de Huelva y el final de la Edad del Bronce en el Occidente de Europa". Ampurias 2: 85-143.

Almagro Basch, M. 1940b: "La cronología de las fíbulas de codo". Saitabi III: 1-5.

Almagro Basch, M. 1952: "La invasión céltica en España". En R. Menéndez Pidal: Historia de España I, 2. Espasa Calpe. Madrid: 1-278.

Almagro Basch, M. 1957: "La fíbula de codo de la Ría de Huelva. Su origen y cronología". Cuadernos de la Escuela Española de Roma IX: 7-45.

Almagro Basch, M. 1957-58: "A propósito de la fecha de las fíbulas de Huelva”. Ampurias XIX: 198-207.

Almagro Basch, M. 1958: Depósito de la Ría de Huel$v a$. Inventaria Archaeologica. España, 1-4: E. 1, Instituto Español de Prehistoria. Madrid.

Almagro Basch, M. 1966: Las estelas decoradas del Suroeste Peninsular. Bibliotheca Praehistorica Hispana VIII, CSIC. Madrid.

Almagro Basch, M. 1975: "Depósito de bronces de la Ría de Huelva”. Huelva, Prehistoria y Antigüedad, Madrid: 213-220.

Almagro-Gorbea, M. 1978: "Las dataciones para el Bronce Final y la Edad del Hierro y su proble- 
mática". En M. Almagro Gorbea y M. Fernández Miranda (eds.): C-14 y Prehistoria de la Península Ibérica. Fundación Juan March, Serie Universitaria 77. Madrid: 101-109.

Arribas Palau, A.; Pareja López, E.; Molina González, F.; Arteaga Matute, O. y Molina Fajardo, F. 1974: Excavaciones en el poblado de la Edad del Bronce "Cerro de la Encina" Monachil (Granada) (El corte estratigráfico n. ${ }^{\circ}$ 3). Excavaciones Arqueológicas en España 81, Ministerio de Cultura. Madrid.

Bartelheim, M.; Contreras Cortés, F.; Moreno Onorato, A.; Murillo-Barroso, M. y Pernicka, E. 2012: "The silver of the South Iberian El Argar Culture: A first look at production and distribution". Trabajos de Prehistoria 69 (2): 293-309.

Blasco Bosqued, M. ${ }^{\text {a }}$ C. 1987: "Un ejemplar de fíbula de codo 'ad occhio' en el Valle del Manzanares". Boletín de la Asociación Española de Amigos de la Arqueología 23: 18-28.

Bleed, P. 2002: "Threes or Chains, Links or Branches: Conceptual Alternatives for Consideration of Stone Tool Production and Other Sequential Activities". Journal of Archaeological Method and Theory 8: 101-127.

Bruins, H. J.; Nijboer, A. J. y Plicht, J. van der 2011: "Iron Age Mediterranean Chronology: a Reply". Radiocarbon 53 (1): 199-220.

Cabré Aguiló, J. 1922: "Una necrópolis de la primera Edad de los Metales". Actas de la Sociedad Española de Antropología, Etnografia y Prehistoria I: 23-36.

Carrasco Rus, J. y Pachón Romero, J. A. 2006a: "Sobre la cronología de las fíbulas de codo tipo Huelva". Archivo de Prehistoria Levantina XXVI: 245-292.

Carrasco Rus, J. y Pachón Romero, J. A. 2006b: "La fíbula de codo tipo Huelva. Una aproximación a su tipología". Complutum 17: 103-119.

Carrasco Rus, J. y Pachón Romero, J. A. 2006c: "Algunas cuestiones sobre el origen oriental de la fíbula de codo tipo Huelva". Revista Tabona 14: 63-92.

Carrasco Rus, J.; Pachón Romero, J. A.; Esquivel Guerrero, J. A. y Aranda Jiménez, G. 1999: "Clasificación secuencial tecno-tipológica de las fíbulas de codo de la Península Ibérica". Complutum 10: 123-142.

Carrasco Rus, J.; Pachón Romero, J. A.; Montero Ruiz, I. y Gámiz Jiménez, J. 2012: "Fíbulas de codo 'tipo Huelva' en la Península Ibérica: nuevos datos y comentarios historiográficos". Trabajos de Prehistoria 69 (2): 310-331.

Carrasco Rus, J.; Pachón Romero, J. A.; Montero Ruiz, I.; González Prats, A. y Gámiz Jiménez, J. 2013: "Sobre las fíbulas de codo sículas 'tipo Monachil' en la Península Ibérica y sus relaciones mediterráneas". Lvcentvm 32: 31-52.

Carrasco Rus, J.; Pachón Romero, J. A. y Pastor Muñoz, M. 1985: "Nuevos hallazgos en el conjunto arqueológico del Cerro de la Mora. La espada de lengua de carpa y la fíbula de codo del Cerro de la Miel (Moraleda de Zafayona, Granada)". Cuadernos de Prehistoria de la Universidad de Granada 10: 265-333.

Carrasco Rus, J.; Pachón Romero, J. A.; Pastor Muñoz, M. y Gámiz Jiménez, J. 1987: La espada de lengua de carpa del Cerro de la Miel (Moraleda de Zafayona) y su contexto arqueológico. Nuevas aportaciones para el conocimiento de la metalurgia del Bronce Final en el sudeste peninsular. Excmo. Ayuntamiento de Moraleda de Zafayona. Granada.

Celestino Pérez, S. 2001: Estelas de guerreros y estelas diademadas. La precolonización y formación del mundo tartésico. Bellaterra Arqueología. Barcelona.

Celestino Pérez, S. 2008: "La precolonización a través de los símbolos". En S. Celestino, N. Rafel y L. Armada (eds.): Contacto cultural entre el Mediterráneo y el Atlántico (siglos XII-VIII ane). La precolonización a debate. Serie Arqueológica 11, Escuela Española de Historia y Arqueología en Roma, CSIC. Madrid: 107-119.

Cradock, P. T. 1976: "The composition of the copper alloys used by the Greek, Etruscan and Roman civilizations.1. The Greeks before the Archaic period". Journal of Archaeological Science III: 93- 113.

Delibes de Castro, G. 1978: "Una inhumación triple de facies Cogotas I en San Román de Hornija (Valladolid)". Trabajos de Prehistoria 35: 225-250.

Delibes de Castro, G. 1981: "Una interesante fíbula del Bronce Final del Cerro del Berrueco (Salamanca)". Guimarâes XVI: 172-182.

Dolfini, A. 2011: "The function of Chalcolithic metalwork in Italy: an assessment based on use-wear analysis". Journal of Archaeological Science 38: 1037-1049.

Eles Masi, P. von 1986: Le fibule dell'Italia settentrionale. Prähistorische Bronzefunde XIV, 5. C. H. Beck. München.

Fantankil, A.; Finkelstein, I. y Piasetzky, E. 2011: "Iron Age Mediterranean chronology: a rejoinder". Radiocarbon 53 (1): 179-198.

Giumilia-Mair, A.; Albanese, R. M. y Lo Schiavo, F. 2010: "The Metallurgy of the Sicilian Final Bronze Age/Early Iron Age necropolis of Madonna del Piano (Catania, Sicily)". Trabajos de Prehistoria 67 (2): 469-488.

González Gómez, C.; Sánchez Sánchez, P. y Villafranca Sánchez, E. 1987: "University of Granada radiocarbon dates IV". Radiocarbon 29 (3): 381-388.

González Román, C.; Adroher Auroux, A. y López Marcos, A. 1995: "El yacimiento de Canto Tortoso (Gorafe, Granada): un enclave comercial del siglo VI a.C. en el Guadiana Menor". Verdolay 7: 150-176. 
Hook, D. R. 2007: “The Composition and Technology of Selected Bronze Age and Early Iron Age Copper Alloy Artefacts from Italy". En A. M. Bietti y E. Macnamara (eds.): Prehistoric Metal Artefacts from Italy (3500-720 BC) in the British Museum. British Museum Research Publication 159. London: 308351.

Karlin, C.; Bodu, P. y Pelegrin, J. 1991: "Processus, Techniques et Chaîne opératoires. Comment les Préhistoriens s'approprient un concept elaboré par les ethnologues". En H. Balfet (ed.): Observer l'action technique. Des Chaînes Opératoires, pourquoi faire? Editions du Centre National de la Recherche Scientifique. Paris: 101-117.

Li, X. J.; Martinón-Torres, M.; Meeks, N. D.; Xia, Y y Zhao, K. 2011: "Inscriptions, filing, grinding and polishing marks on the bronze weapons from the Qin Terracotta Army in China". Journal of Archaeological Science 38: 492-501.

Lo Schiavo, F. 2010: Le Fibule dell'Italia meridionale e della Sicilia dall'età del bronzo recenté al VI secolo a.C. Prähistorische Bronzefunde 14.14. Franz Steiner Verlag. Mainz.

Mazar, E. 2004: The Phoenician Family Tomb n. 1 at the Northen Cemetery of Achziv (10th- $6^{\text {th }}$ Centuries $B C E)$ : Sam Turher Expedition, Final Report of the Excavations. Cuadernos de Arqueología Mediterránea 10. Barcelona.

Molina González, F. 1977: La cultura del Bronce Final en el Sudeste de la Península Ibérica. Resúmenes de Tesis Doctorales de la Universidad de Granada 178. Granada.

Molina González, F. 1978: "Definición y sistematización del Bronce Tardío y Final en el Sudeste de la península Ibérica". Cuadernos de Prehistoria de la Universidad de Granada 3: 159-233.

Montero Ruiz, I. 2008: “Ajuares metálicos y aspectos tecnológicos en la metalurgia del Bronce FinalHierro en el Sudeste de la Península Ibérica". En A. Lorrio: Querénima. El Bronce Final del Sureste de la Península Ibérica. Biblioteca Archaeologica Hispana 27. Real Academia de la Historia. Madrid: 499-516.

Morgado Rodríguez, A. y Baena Preysler, J. 2011: "Experimentación, Arqueología experimental y experiencia del pasado en la Arqueología actual". En A. Morgado, J. Baena Preysler y D. García (eds.): La investigación experimental aplicada a la Arqueología. Universidad de Granada. Granada: 21-28

Pelegrin, J.; Karlin, C. y Bodu, P. 1988: “Chaîne opérative': un outil pour le préhistorien". En J. Tixier (ed.): Technologie Préhistorique. Notes et Monographies Techniques du Centre de echerches archéologiques 25, Edition du CNRS. Paris: 55-62.

Perea Caveda, A. y García Vuelta, O. 2012: "Gold usage. Wear marks and/or deterioration in site con- ditions". N. Meeks, C. Cartwright, A. Meek y A. Mongiatti (eds.): Historical technology, materials and conservation: SEM and Microanalysis. British Museum, Archetype Pub. Londres.

Plicht, J. van der; Bruins, H. J. y Nijboer, A. J. 2009: "The Iron Age around the Mediterranean: a High Chronology perspective from the Groningen radiocarbon database". Radiocarbon 51 (1): 213-242.

Quintana López, J. y Cruz Sánchez, P. J. 1996: “Del Bronce al Hierro en el centro de la Submeseta Norte (consideraciones desde el Inventario Arqueológico de Valladolid)". Boletín del Seminario de Estudios de Arte y Arqueología LXII: 9-78.

Reimer, P. J.; Baillie, M. G. L.; Bayliss, A.; Beck, J. W.; Blackwell, P. G.; Bronk Ramsey, C.; Buck, C. E.; Burr, G. S.; Edwards, R. L.; Friedrich, M.; Grootes, P. M.; Guilderson, T. P.; Hajdas, I.; Heaton, T. J.; Hogg, A. G.; Hughen, K. A.; Kaiser, K. F.; Kromer, B.; McCormac, F. G.; Manning, S. W.; Reimer, R. W.; Richards, D. A.; Southon, J. R.; Talamo, S.; Turney, C. S. M.; Plicht, J. van der y Weyhenmeyer, C. E. 2009: "IntCal09 and Marine09 radiocarbon age calibration curves, 0-50.000 years Cal BP”. Radiocarbon 51 (4): 1111-1150.

Rovira Llorens, S. 1987: "Algunos aspectos de la tecnología metalúrgica en el Bronce Final y la Edad del Hierro". Boletín de la Asociación Española de Amigos de la Arqueología 23: 53-57.

Ruiz-Gálvez Priego, M. 1995: Ritos de paso y puntos de paso. La Ría de Huelva en el mundo del Bronce Final Europeo. Complutum Extra 5, Universidad Complutense. Madrid.

Santos Zalduegui, J. F.; García de Madinabeitia, S.; Gil Ibarguchi, J. I. y Palero, F. 2004: “A lead isotope database: the Los Pedroches-Alcudia Area (Spain); Implications for Archaeometallurgical connections across Southwestern and Southeastern Iberia". Archaeometry 46: 625-634.

Schüle, W. 1969: Die Meseta-Kulturen der Iberischen Halbinsel. Mediterrane und eurasische Elemente in früheisenzeitlichen Kulturen Südwesteneuropas. Madrider Forschungen 3, De Gruyter. Berlin.

Sellet, F. 1993: "Chaîne operatoire: the concept and its applications". Lithic Technology 18 (1-2): 106-112.

Sharon, I.; Gilboa, A.; Jull, T.; Boaretto, E. 2007: "Report on the first stage of the Iron Age Dating Project in Israel: supporting a Low Chronology". Radiocarbon 49 (1): 1-46.

Soriano, I. y Gutiérrez, C. 2009: "Use - wear analysis on metal: the raw material and metallurgical work process influence". En Associazione Italiana di Metallurgia (eds.): $2^{\text {nd }}$ International Conference Archaeometallurgy in Europe 2007 (Aquileia-Italy 2007). Selected Papers. Milano: 115-124.

Torres Ortiz, M. 1999: Sociedad y mundo funerario en Tartessos. Real Academia de la Historia. Madrid. 
Torres Ortiz, M. 2002: Tartessos. Bibliotheca Archaeologica Hispana 14, Real Academia de la Historia. Madrid.

Torres Ortiz, M. 2008a: 'Los 'tiempos' de la precolonización”. En S. Celestino, N. Rafel y L. Armada (eds.): Contacto cultural entre el Mediterráneo y el Atlántico (siglos XII-VIII ane). La precolonización a debate. Serie Arqueológica 11, Escuela Española de Historia y Arqueología en Roma, CSIC. Madrid: 59-91.

Torres Ortiz, M. 2008b: "The Chronology of the Late Bronze Age in Western Iberia and the Beginning of the Phoenician Colonization in the Western Mediterranean". En D. Brandherm y M. Trachsd (eds.): $A$ New Dawn for the Dark Age? Shifting Paradigms in Mediterranean Iron Age Chronology. British Archaeological Reports, International Series 1871, Archaeopress. Oxford: 135-147.
Torres Ortiz 2012: "La precolonización en Extremadura”. En J. Jiménez Ávila (ed.): Sidereum Ana II. El río Guadiana en época postorientalizante. Anejos de Archivo Español de Arqueología LXII, Instituto de Arqueología de Mérida. Mérida: 455-475.

Turco, M. ${ }^{a}$ G. 2000: La necrópolis di Cassibile. Cahiers du Centre Bérard XXI, Centre Jean Bérard. Nápoles.

Urbina Martínez, D. y García Vuelta, O. 2010: “Las Lunas, Yuncler (Toledo). Un depósito de materiales metálicos del Bronce Final en la Submeseta Sur de la Península Ibérica". Trabajos de Prehistoria 67 (1): 175-196.

Urbina Martínez, D. y García Vuelta, O. 2013: “Cronología radiocarbónica de Las Lunas (Yuncler, Toledo), un gran poblado de fines de la Prehistoria en la Meseta". Trabajos de Prehistoria 71 (2): 352360 .

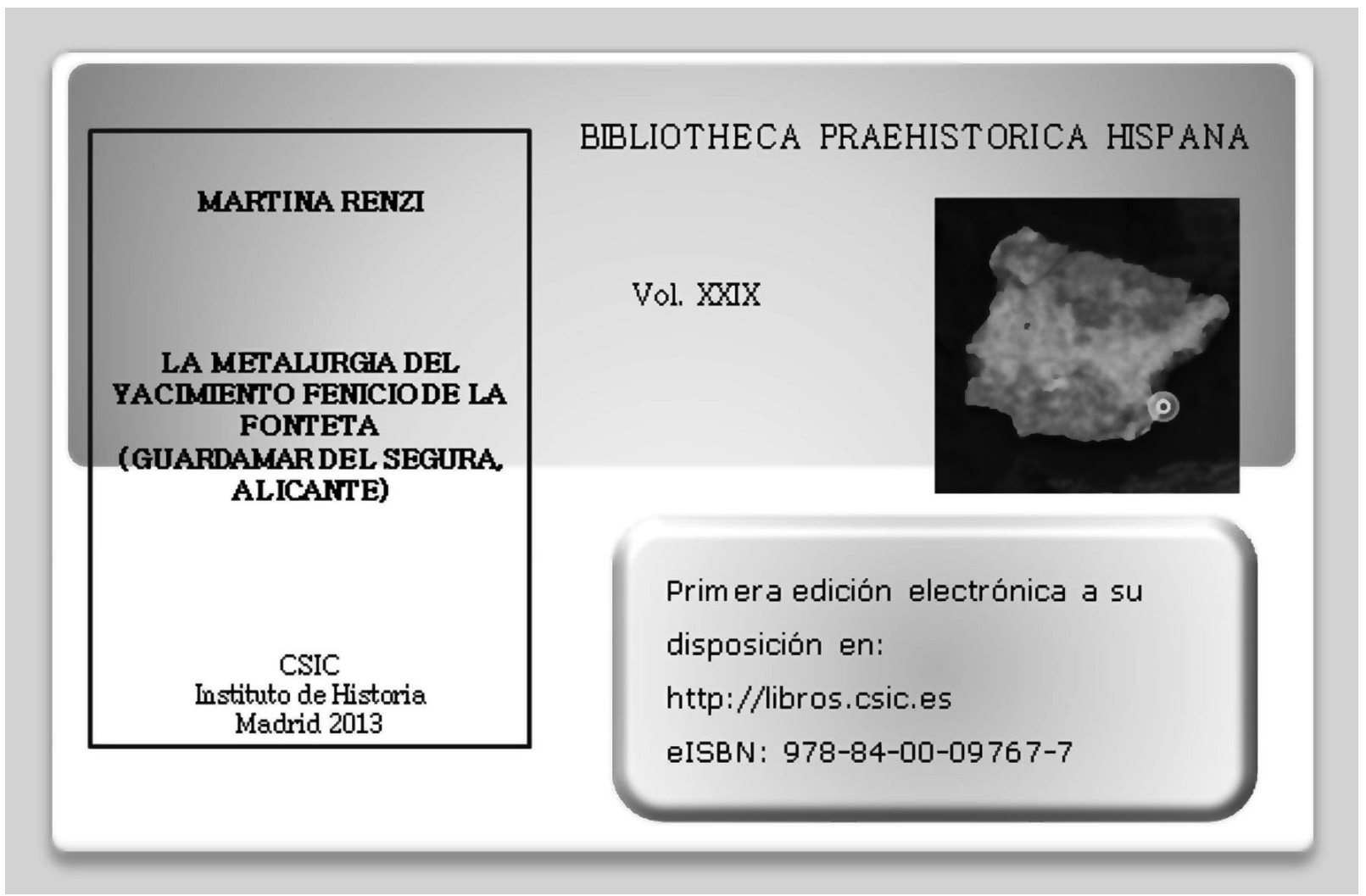

Trab. prehist., 71 , N. $^{\circ} 1$, enero-junio 2014, pp. 95-112, ISSN: 0082-5638 doi: $10.3989 /$ tp. 2014.12126 